\title{
Research on the Implementation Situation and Countermeasures of Financial Policy of the Public Sports Service in China
}

\author{
Donghua Zhou \\ Wuhan Business University \\ Wuhan, China
}

\author{
Lulu Ju \\ Wuhan Business University \\ Wuhan, China
}

\begin{abstract}
The paper researched the current situation about financial policy of public sports service in China by using literature, induction analysis method. The result shows that: the distinction of financial investment is obvious in eastern, central, western regions and urban, rural areas are also unbalanced while the total financial investment has been consistent growth. The implementation of Central policy is inefficient through local governments. According to the analysis of the current situation, there are several reasons are thought to lead to it: Financial policies and regulations are not perfect; Fiscal policy makers lack authority; The sports awareness of magistrates is not comprehensive; The fiscal ability of local government is limited; People lack sports awareness; the Lack of human resources in public sports services such as social sports instructors. According to this, seven proposals are put forward to promote the development of the public sports service in China.
\end{abstract}

Keywords-public sports service; financial policy; implementation situation; countermeasures

\section{INTRODUCTION}

With the introduction of The sports development plan in 13th Five Year, The National Fitness Program 2016-2020, and Some opinions on speeding up the development of sports industry and promoting sports consumption, all these policy stimulated the enthusiasm of the mass sports, the demand of public sports service is becoming more and more diversified, the government must invest manpower, material and financial resources to give fiscal security. The government must be formulated and issued a series of financial policy and regulations in order to ensure that the public sports service needs of the masses will be met. ${ }^{[1-2]}$

The public sports service financial policy refers to that the country provides the public sports service fiscal work guidelines to society, which includes the general thought, the main body frame, the specific rules and methods, such as the policy documents about financial investment, transfer payments, supervision and evaluation security and so on. ${ }^{[3]}$

\section{THE IMPLEMENTATION SitUATION OF THE PUBLIC SPORTS SERVICE FINANCIAL POLICY}

\section{A. Fiscal Policy Implementation Effect of Public Sports Services from the Horizontal Perspective}

Although public sports service total financial investment increase steadily year by year in China, the total investment is not enough, and regional distribution is not balanced. Financial investment is mainly in central and eastern areas, the western area is the least. The sports expenditure amount of eastern regions is about 3.8 times that of the central region according to survey. In western region, it is 1.4 2.2 times that of central region except 2011.The difference between the provinces is much wide. ${ }^{[4]}$ All kinds of public sports facilities construction investment in central and eastern, the difference is significantly greater than west. This kind of unfair and imbalance situation not only reflects in the east, in the central and western regions, but also in the urban and rural areas. In urban-rural dual structure, public sports service financial spending is severe to tend to urban. ${ }^{[5]}$

\section{B. Fiscal Policy Implementation Effect of Public Sports Services from the Vertical Perspective}

As people's sports demands grow, the national financial investment to the sports public service is also increased greatly. The coverage that the government of all levels put the national fitness funding into the budget will be increased year by year, which is mentioned in Blue Book Of sports For All. The rate at provincial level is $100 \%$ with a flat. It has increased $0.2 \%$ comparing with last year which is $98.8 \%$ at regional level. It has increased $13 \%$ comparing with last year which is $95 \%$ at county level. The budget coverage from central to local is in "Table I". From provincial level to regional level and county level, the financial budget coverage rate gradually reduced which indicates the implementation of policy is insufficient from central to regional. It is a long process for a policy from issued by CPC TO Implemented by regional even completed. It has been 21 years from Outline of the Nationwide Body-building Plan issued by CPC in June, 1995. What is the condition like in regional implementation? Dose the situation of implementation in line with the policy issued by CPC 
initially? Data shows that, the number of sports population, the construction of facilities, the security system of sports, the development of national fitness sports activity, the people health and so on have greatly improvement during equipment Outline of the Nationwide Body-building Plan is implemented. However, according the survey, many provinces and cities exist the utilization rate of public sports fitness resource is low, the fitness equipment is worn out, the fitness awareness of the masses is not strong, insufficient fiscal input in public sports service. ${ }^{[6]}$

TABLE I. CENTRAL TO LOCAL FITNESS FundS INTO THE BUdGET COVERAGe RATE

\begin{tabular}{|c|l|l|}
\hline The region & $\begin{array}{c}\text { Financial } \\
\text { investment }\end{array}$ & $\begin{array}{c}\text { Lottery welfare } \\
\text { investment }\end{array}$ \\
\hline Provincial division & $96.77 \%$ & $100 \%$ \\
\hline Prefecture division & $96.98 \%$ & $90.63 \%$ \\
\hline County division & $83.03 \%$ & $74.13 \%$ \\
\hline \multicolumn{2}{|c|}{ a. The source of the data from the 2014 blue book of mass sports }
\end{tabular}

In conclusion, one hand, financial input for public sports service increase year by year, the coverage rate of putting the public sports service funding into the budget increase people get some meet the demand of sports. On the other hand, the financial input of public sports is imbalance in eastern, central and western regions, the financial policy isn't implemented perfectly, investment is imbalance in urban rural areas, the resource utilization of public sports service is low.

\section{THE REASON ANALYSIS OF IMPLEMENTATION Situation of Public Sports SeRvice FinANCial Policy}

\section{A. From the Perspective of Policy Makers}

1) Financial policies and regulations are not perfect, weak operability.

Whether the policy is scientific or not is a key factor in the effective implementation of policies. The factors that influence scientific policy include the policy implementation, operability, word accuracy etc. Many of the documents used in the selection of specific and vague concept of the word which weakened the authority of the policy. For example, "attention to the elderly and woman's physical and health problems, and actively support them to participate in physical fitness activities", "Actively create fitness conditions for intellectuals" (outline of the nationwide bodybuilding plan) have many policy empty words like "support", "actively", "encourage" that are optional execution strength. Local governments will take different measures according to their preferences, some local governments even the use of loopholes in the text, do not implement the policy, so that the lack of enforceability of the policy, it is difficult to implement.

\section{2) Policy makers lack of authority.}

The authority of the policy is that the policy has binding force on the policy executor and policy object, to regulate their behavior in accordance with the policy. The government issued documents, policies and plans lack of authority, thus giving the local executive misinterpret the loophole. The authority of policy generally refers to the position and level of the status of the constitutors. The higher the level of authority, the greater the executor of the next level of executive dominance. As of February 2014 three at the municipal level into the "overall coverage rate is close to 97\%, the district overall coverage is close to 93\%. 2013 national fitness costs for the local people increased by $88.91 \%$ over the year of 2012, which 10 billion 572 million yuan of financial allocations increased by $192.04 \%$ points in than in 2012.The policy can be effectively implemented and implemented the most important thing is that the three into the policy is issued by the State Council such an authoritative body which has a great role in promoting the implementation of the policy process.

\section{B. From the Perspective of Policy Implementers}

1) Under the guidance of political achievements, local officials pays less attention to public sports services.

Public sports service fiscal policy in the implementation process, the efficiency is not high. After the promulgation of the policy, the most important step is to implement. If there is no effective implementation of a policy, it will lose its meaning. Under the influence of "the whole nation system", the development of the cause of sports is biased towards competitive sports; a large number of funds will be given priority to competitive sports. In many local governments, the promotion of officials linked to the number of gold medals for athletes which led to the local officials to produce the concept of "focus more attention on athletics sports than on mass sports". Influence of the champion it is local government and the central government that has divided interests. The central government is considering the overall national demand for sports interests, while the local government makes their achievements of themselves. Under the guidance of political achievements, as a rational economic man, local officials only see the competitive sports in the development of sports in China While ignoring the development of public sports service is an important direction of the future development of sports.

2) The local government act subject ability, too much responsibility, weak property rights.

Chinese vast territory and abundant resources, vast differences in the four corners of the world, the difference of economic development level is big. The lack of manpower, material resources and financial resources in underdeveloped areas. The ability of grassroots sports departments to support public sports services is constrained by the higher level government. The major reform of the tax system makes local finance weak, especially in the central and Western Regions. While the power is overweight, the governance and the property rights of the asymmetry leads to the local public sports service for the enthusiasm that is not high cannot immediately see the result, and one can't make bricks without straw.

3) Lack of human resources in public sports services.

No matter how good the policy is, it must need a certain amount of manpower to perform in order to achieve the expecting effect, and the terminal executor of the current 
public sports services, social sports instructors are shortage seriously especially in rural areas. According to the investigation, in 2011, China's total population reached 1 billion 347 million 350 thousand, the number of social sports instructors is 650 thousand. The per capita of social sports instructor is 1:2000, equipment to two thousand people only one social sports instructor to provide services for them. This also includes part of the social sports instructors who are not engaged in public sports services. The number of social sports instructors cannot meet the needs of the development of public sports services. But the public sports service generally only provides the fitness equipment, the place, but lacks the social sports instructor's specialized organization and the professional instruction. People can't master the proper use of fitness equipment, let alone organize some interesting games. These public sports service resources have become a kind of decoration. As a result, people are not satisfied with the public sports service. The government spent money, but people did not feel it. ${ }^{[7-8]}$

\section{From the Perspective of Policy Audience}

1) People lacking of sports awareness.

The audience response to a policy reflects the success or failure of a policy, the response of the audience is influenced by many factors. For example, citizen's sports consciousness, sports science knowledge and so on. Economically backward areas, the lack of awareness of physical education, especially in rural areas, mainly women and young children almost have no sense of sports. Although some people have an understanding of the sport, but most of them stay in a simple sports concept that sport is running, staying at the level of body movement. They have not realized that sport is a kind of activity that promotes the development of human beings by the means of physical activity.

2) Low utilization rate of public sports services, low public satisfaction

According to the investigation and study of many scholars found that many areas of public sports facilities, equipment and facilities are not full used of and become the basic use of furnishings. Due to the lack of sports health propaganda and the lack of sports instructors, and the people's awareness of the importance of physical exercise is not enough, resulting in the use rate of public sports service is not high. Due to inadequate supply of services, service quality is not high; people are generally not satisfied with the public sports services.

\section{COUNTERMEASURES TO IMPROVE THE PRESENT} Situation of Public SPORTS SERVICE FinANCE Policy

\section{A. To Improve the Central Financial Input, Improving the Transfer Payment}

A policy implementation is the lack of necessary resources, as one can't make bricks without straw. China's transfer payment system is composed of general transfer payment and special transfer payment. The former is the balance of regional differences in the realization of equalization; governments have the right to use the funds of self-help. ${ }^{[9]}$ The general transfer payments, based on the field investigation should be transferred on the funds that will be used wisely for buying the public fitness resources, hiring and organizing the interest of fitness instructors, and mass sports events. However, attention should be paid to the general purpose of the transfer of funds, supervision should be given to the where the funds flow to and how to use them.

\section{B. Making Scientific Policy, Improving the Legal System}

Improving the policy authority is to reduce the fuzzy words in the ideographic files, to increase the mandatory words, right words, to improve the implementation of the control of consciousness, to increase the quantitative standard; in order to make the next level departments can complete the tasks and inspect the implementation of the policy. In terms of policies and documents, the implementation of the provisions and the specific implementation of the program should avoid using empty words. The State Council and other senior government should increase the support for the construction of public sports services, should make appropriate policies to improve the construction of public sports services. We will accelerate the formulation, implementation and implementation of the law on the protection of public sports services, and to form a major binding force in the form of law. Finally, the standardization and equalization of basic public sports service will be carried out to promote the stable development of public sports service.

\section{Encouraging Citizens Participating Sports}

To cultivate citizen's awareness of sports participation should develop from children. We should increase the dissemination of scientific knowledge of sports from primary school education, to train lifelong sports awareness. At the same time, we should strengthen the construction of the professional team of physical education teachers, to improve the physical education of primary and secondary school physical education teachers, to increase the propaganda of sports scientific knowledge in the residential committee and community. The local government should hold more public welfare lectures. Only arming the mind with scientific knowledge can we improve the depth and breadth of citizen participation, and the acceptability and enforceability of policy.

\section{Balancing Regional Difference}

First of all, the most important thing is to ensure that the central government continues to increase investment, the proportion of financial investment should put more to the West areas. Secondly, secondly, to promote the diversification of sources of public sports service of finance, attracting social resources to give more financial support to the Midwest areas, so as to realize the equalization of public sports service development in China.

\section{E. Strengthening Sports Awareness of Local Government Officials}

Local officials should recognize that the health right is the basic right that every citizen should enjoy. In the appointment of local officials should pay attention to the 
investigation and audit whether they pay more attention to sports, to strengthen the construction of human resources team of government staffs. The government should establish a complete performance appraisal system, not only focusing on the number of gold medals linked to performance, but also the development of mass sports and civic satisfaction into the assessment system to monitor local government officials.

\section{F. Improving the Utilization Rate of Social Sports Instructors and Other Professionals}

The government should improve and introduce relevant policies and regulations to increase the support for the development of social sports instructors, to increase the support of the relevant funds and their remuneration. Strengthen the sports administrative departments of social sports instructor recommended efforts, make sure social sports instructors have something to do. Each prefecture level city sports professionals should be used of the reasonably, organizing social sports instructors pass the examination to achieve instructor qualification, reasonably distribute them to local areas. Primary and secondary school physical education teachers resources can also be used, encouraging they use of weekends to make people to know the social sports, so as to improve the terminal execution ability of the policy. ${ }^{[9-10]}$

\section{G. Establishing and Improving the Financial Supervision Mechanism}

It is difficult to find specific data of government spending, investment in the official website, which is not open and transparent. Therefore, the first step is to establish an open mechanism, financial investment and spending should be noticed online regularly. After the announcement, the government can open the public mailbox and online service platform to accept social supervision, the establishment of the third party oversight mechanism should be set up, only civil supervision is not enough. The central government should regularly send specialist group to do investigation, to make sure funding of sports public service project is used correctly.

\section{H. Reasonable Allocation Mechanism to Improve the Central and Local Powers}

Public sports service is the power of the central and local governments have. Therefore, the public sports service should be based on its objectives and specific tasks, the central government and local governments at all levels should take financial responsibility, in order to determine the levels of government's power and responsibilities, to make specific provisions for local government to fulfill the responsibilities of public sports service by combining the specific situation. According to the rights and responsibilities of public sports service to make sure what the government should do, to clear the government's responsibility on basis of the scope of government administrative division of fiscal expenditure and the powers symmetry classification. to formulate a scientific and reasonable financial allocation proportion and service standards by taking fiscal power and public service and other powers as the principle. ${ }^{[11-12]}$

\section{CONCLUSIONS}

Above all, as a kind of public goods, public sports services are designed to meet the needs of people's sports, to enrich people spare time, to promote the quality of life and to improve their health. But at present, there are some problems in the public finance policy of our country, such as the regional difference and the difference between urban and rural areas. Therefore, it is necessary to improve the government's ability to support financial strength, but also to strengthen sports awareness local government officials and residents. Governments at all levels and local departments should be concerned about the public demand of public sports services in order to develop more effective public sports service fiscal policies and regulations.

\section{REFERENCES}

[1] http://www.sport.gov.cn/n316/n340/c723004/content.htm1

[2] http://www.gov.cn/xinwen/2016-04/08/content_5062329.htm

[3] Hukai.Study on fiscal policy of our country's sports public service [D], Wuhan Institute of Physical Education, 2014, 6.

[4] Lu Zhicheng. Research on the fairness of fiscal expenditure policy the public sports [J], China sports science, 2014 (8)3-12.

[5] ZhaiQiuYang, Cui Guangsheng. China's urban and rural basic public services equalization research - based on the comparative analysis of several eastern, central and western provinces and cities [J], Journal of realistic, 2015(7):49-56.

[6] Ren Chengfang. National fitness program outline the history review of the implementation of effect [D], Jiangxi Normal University, 2011.

[7] Zheng Fenglei. Policy authority weakening countermeasure analysis [J], Value engineering, 2010.29(30): 87-87.

[8] John fung. Implementation is the key - John fung, director of the national mass sports in 2012 working meeting of the summary of the speech [J], Journal of New Sports, social sports instructors,2012(1): 24-25.

[9] Hou Jie, Bai Jianhua. Concerning the necessity of the industrialization of social sports instructors [J], People's BBS: the tenday, 2011 (4).

[10] Jiang Guangyi.The current situation of the development of social sports instructors in Jilin province analysis [J], Journal of Jilin Institute of Sport, 2013, 29(4): 42-47.

[11] Huakai,,zi-li LAN,zhi-yun liu.The present situation, problems and countermeasures of public sport service financing [J],Journal of Tianjin Sports College, 2014, 29(6): 473-477.

[12] Zi-li LAN, Ke-qiang Cao, LuoYing.Public sports service financial security of based on the governance [J], Journal of Sport. 2016, 23(6):35-40. 